\title{
FECAL STEROLS AND LINEAR ALKYLBENZENES IN SURFACE SEDIMENTS COLLECTED AT 2009/10 AUSTRAL SUMMER IN ADMIRALTY BAY, ANTARCTICA
}

http://dx.doi.org/10.4322/apa.2014.075

\section{César de Castro Martins ${ }^{1, *}$, Sabrina Nart Aguiarr,2, Márcia Caruso Bícego ${ }^{3}$, Liziane Marcella Michelotti Ceschim ${ }^{1}$, Rosalinda Carmela Montone ${ }^{3}$}

\author{
${ }^{1}$ Centro de Estudos do Mar, Universidade Federal do Paraná - UFPR, CP 61, CEP 83255- 976, Pontal do Paraná, PR, Brazil \\ 2Departamento de Geoquímica, Universidade Federal Fluminense - UFF \\ Morro do Valonguinho, s/n, Niterói, CEP 24020-150, Rio de Janeiro, RJ, Brazil \\ ${ }^{3}$ Instituto Oceanográfico, Universidade de São Paulo - USP, Praça do Oceanográfico, 191, CEP 05508-120, São Paulo, SP, Brazil

$$
\text { *e-mail: ccmart@ufpr.br }
$$

\begin{abstract}
Fecal sterols (coprostanol and epicoprostanol) and linear alkylbenzenes (LABs) are efficient geochemical markers of sewage input in marine environment because they present stability and resistance to degradation processes. The Antarctic region is considered one of the best preserved environments in the world, however the discharge of sewage directly into the marine environments around scientific stations has resulted in changes in this pristine site. In order to assess the distribution and concentration of sewage indicators from Comandante Ferraz Brazilian Antarctic Station, sediments were sampled during the 2009/10 austral summer at four points: (1) Refuge II (Mackelar Inlet), (2) Ferraz, (3) Ulmann and (4) Botany Point (Martel Inlet) at depths around of 20 until $30 \mathrm{~m}$. The organic markers were determined by gas chromatography with flame ionization (GC-FID) and mass spectrometer detectors (GC-MS). Concentrations offecal sterols and LABs ranged from $<0.01$ to $0.17 \mu \mathrm{g} \mathrm{g}^{-1}$ and $<1.0$ to $46.5 \mathrm{ng} \mathrm{g}^{-1}$ dry weight, respectively. In general, the higher concentrations were found only locally in the vicinity of Ferraz Station at Martel Inlet. The maximum concentration to fecal sterols was close to the value previously calculated as background level for Martel Inlet $\left(0.19 \mu \mathrm{g} \mathrm{g}^{-1}\right)$ and it was lower than the concentration found in the same points during the austral summer of 2003/04 $\left(0.93 \mathrm{\mu g} \mathrm{g}^{-1}\right)$ while for the LABs, the concentration remained practically constant ( $\left.35 \mathrm{ng} \mathrm{g}^{-1}\right)$. Despite low concentrations of sewage organic markers, monitoring programs are required to determine continuing trends and prevent the increase of anthropogenic impacts.
\end{abstract}

Keywords: sediments, sterols, linear alkylbenzenes, Antarctica

\section{Introduction}

Sewage organic markers, as fecal sterols and linear alkybenzenes (LABs) are chemical compounds with characteristics such as degradation resistance and specificity according to the origin. They have been successfully used as molecular tracers of domestic wastes contamination in different regions, including the Antarctic (Martins et al., 2005; Montone et al., 2010). Coprostanol ( $5 \beta$-cholestan-3 $\beta$-ol) have been widely used as fecal contamination markers because they are present in human feces while epicoprostanol ( $5 \beta$-cholestan- $3 \beta$-ol) indicates the level of treatment of the fecal matter as it is formed during the extensive anaerobic sewage treatment of wastewaters. Also, LABs are present at levels from 1 to $3 \%$ in surfactants and detergents with linear alkylbenzene sulphonates (LASs), and they are frequently discharged via sewage outfalls together with fecal matter (Martins et al., 2010).

Gröndahl et al. (2008) surveyed 71 Antarctic stations and found that $37 \%$ of permanent stations and $69 \%$ of summer stations lacked any form of sewage treatment. On the other hand, some stations, such as Comandante Ferraz Brazilian Antarctic Station (EACF) have implemented sewage- 
treatment procedures that clean their effluent. However, the (un)treated sewage containing domestic waste is discharged directly into the marine environment and these discharges should be monitored to describe the extent of sewage contaminantion from Antarctic stations.

The aim of this report is to evaluate the sewage contribution from Ferraz station into Admiralty Bay and to compare the historical trend reported in previous studies. This evaluation is based on the results of sewage geochemical indicators from the upper layer of sediments sampled during the austral summer of 2009/10 and previous results (1997-2004). In Antarctica, monitoring the extent of sewage input dispersal is essential as Antarctic
Treaty signatory nations must conform to the Protocol on Environmental Protection.

\section{Materials and Methods}

\section{Study area}

The study area is the Martel Inlet, in Admiralty Bay, King George Island located in the South Shetland Islands, Antarctic Peninsula (62 $02^{\prime} \mathrm{S}$ and 58 $21^{\prime} \mathrm{W}$ ) (Figure 1).

Admiralty Bay has an area of $131 \mathrm{~km}^{2}$, reaches depths of up to $530 \mathrm{~m}$ and has a coastline with many bays (Santos et al., 2007), being the largest bay of King George Island, one of the South Shetlands Islands. There are three large inlets in Admiralty Bay: Martel, Mackelar and Ezcurra
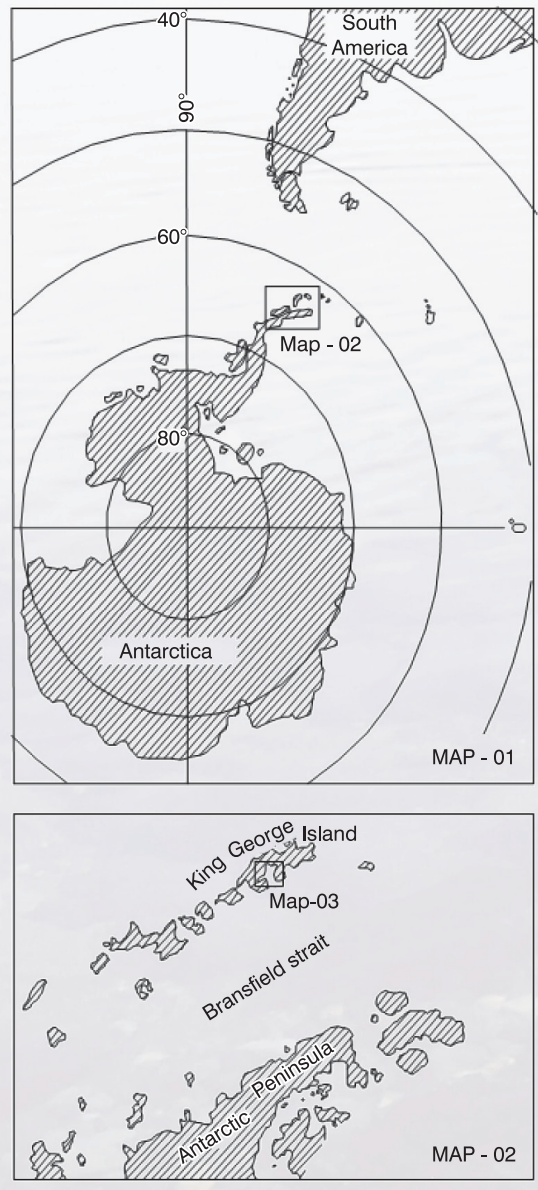

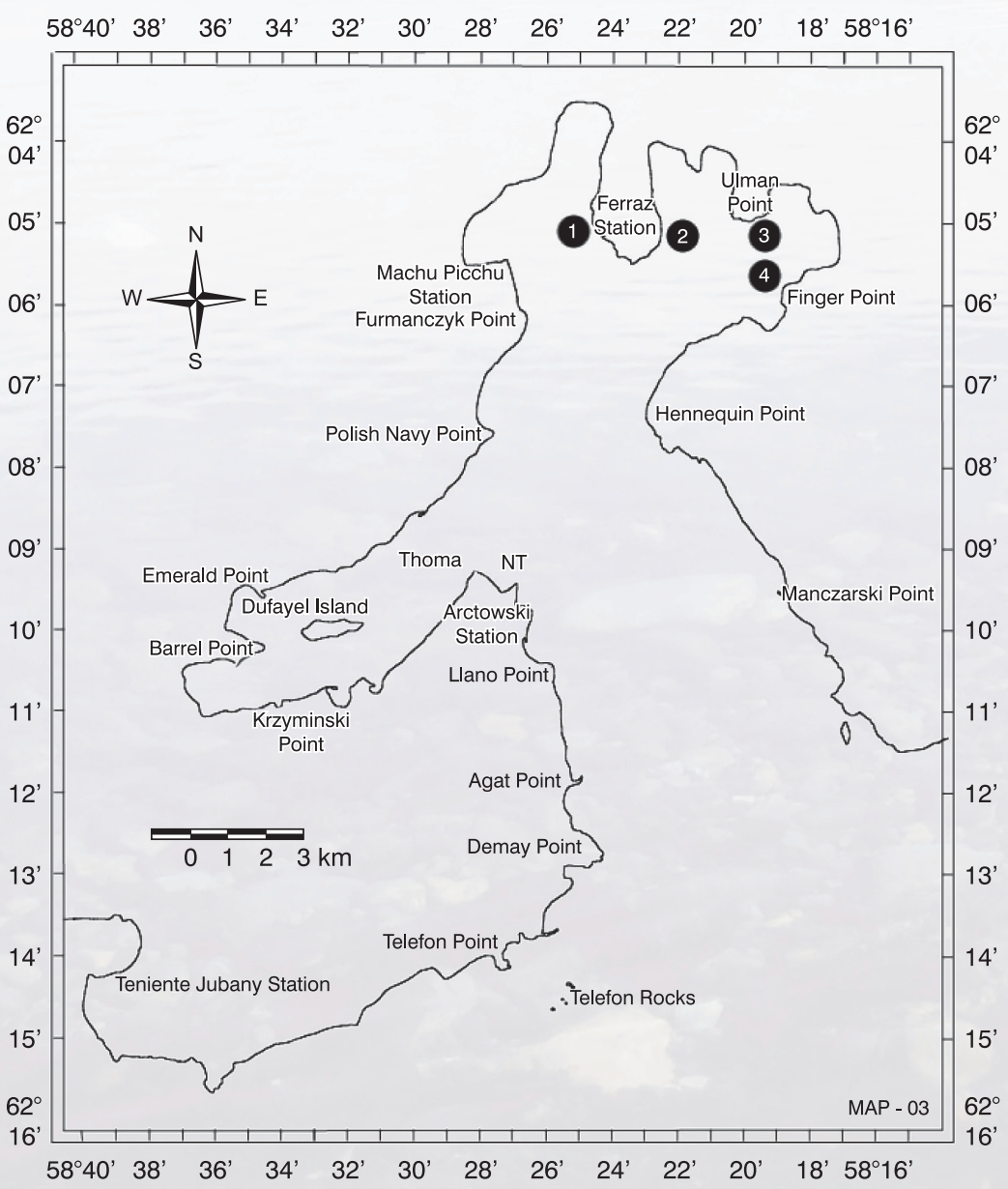

Figure 1. Sampling stations at Admiralty Bay, King George Island, Antarctica. (1): Refuge II (REF); (2): Comandante Ferraz Brazilian Antarctic Station (FER); (3): Ulmann Point (ULM), and; (4): Botany Point (BTN). Table extracted from Martins et al. (2012). 
and each of them holds a research station. The Mackelar and Martel Inlets constitute the North part of the Bay while the Ezcurra Inlet is in the West.

\section{Sampling}

Sediment was obtained from a box core sampler $(25 \times 25 \times 55 \mathrm{~cm})$ during the austral summer of $2009 / 10$ at four points: (1) Refuge II (REF) (Mackelar Inlet); (2) Ferraz (FER); (3) Ulmann (ULM), and; (4) Botany Point (BTP) (Martel Inlet) (Figure 1), at depths around of 20 until 30 $\mathrm{m}$. The upper sediment layers (first $2 \mathrm{~cm}$ ) were used for organic markers analyses.

\section{Analytical procedure}

The analytical method used for the analysis of sterols in sediments is described in Kawakami \& Montone (2002). Around $20 \mathrm{~g}$ of sediment from each site were extracted using a Soxhlet system for $8 \mathrm{~h}$ with $70 \mathrm{~mL}$ of ethanol. The ethanol extract was reduced to c. $2 \mathrm{~mL}$ by rotoevaporation and submitted to a clean up with column chromatography using $2 \mathrm{~g}$ of $5 \%$ deactivated alumina and elution with $15 \mathrm{~mL}$ of ethanol. The extracts were evaporated to dryness and derivatized to form trimethylsilyl ethers using BSTFA (bis(trimethylsilyl)trifluoroacetamide) with 1\% TMCS (trimethylchlorosilane) for 90 minutes at $65^{\circ} \mathrm{C}$. The mixture of TMS-sterols derivatives was determined by the injection of $2 \mu \mathrm{L}$ into a gas chromatograph equipped with a flame ionization detector (GC-FID).

The procedure for analyses of LABs is based on UNEP (1992). About $25 \mathrm{~g}$ of dry sediment samples were Soxhletextracted with hexanes/dichloromethane (1:1) for an 8 -hour period. The solvent extract was concentrated in a rotary evaporator to a volume of approximately $2 \mathrm{~mL}$. The extract was fractionated by adsorption liquid chromatography into aliphatic and aromatic hydrocarbons using a column of alumina and silica gel, and hexanes and $30 \%$ dichloromethane/hexanes for aliphatic and LABs (F1) and aromatic (F2) fractions as eluent, respectively. The fractions were concentrated again in a rotary evaporator, transferred to a vial, and then the volume was adjusted to $1 \mathrm{~mL}$ exactly using a stream of $\mathrm{N}_{2}$ gas. Instrumental details for both analyses are described by Montone et al. (2010).

\section{Results}

Concentrations of fecal sterols and total concentration of linear alkylbenzenes (total LABs) containing alkyl chains ranging from 10 to 14 carbon atoms in the superficial sediments at Admiralty Bay are shown in Table 1.

\section{Discussion}

The values for fecal sterol (coprostanol + epicoprostanol) ranged from not detected $\left(<0.01 \mu \mathrm{g} \mathrm{g}^{-1}\right)$ (REF-B) to $0.17 \mu \mathrm{g} \mathrm{g}^{-1}$ (FER-A). It was observed that the sites located near the sewage outfall (FER-A) showed the highest concentrations, indicating sewage contribution to the sediments. However, these levels were lower comparing to the maxima found in the vicinity of other Antarctic stations, e.g., Davis Station, Australia $\left(1.28 \mu \mathrm{g} \mathrm{g}^{-1}\right)($ Green \& Nichols, 1995) and Rothera station, United Kingdom $\left(0.85 \mu \mathrm{g} \mathrm{g}^{-1}\right)$ (Hughes \& Thompson, 2004).

The contribution of the sewage input to the sediments of Admiralty Bay has been monitored since 1997/98 using fecal sterols as indicators of sewage contribution. Martins et al. (2002) have shown that the critical point was Ferraz Station sewage outfall, which had the highest concentration of these molecular markers. In a more recent study undertaken in the summer of 1999/00, Martins et al. (2005) compared fecal sterols and microbiological indicators. They observed that the sewage contamination was restricted to the vicinity of Ferraz Station and decreased with distance from the outfall. The fecal contribution from the sewage outfall could be detected further away only by molecular tracers rather than microbiological indicators. Previous data about

Table 1. Concentration (in $\mu \mathrm{g} \mathrm{g}^{-1}$ ) of fecal sterols (coprostanol and epicoprostanol) and Total LABs (in ng $\mathrm{g}^{-1}$ ) in sediments collected at REF, FER, ULM and BTP at depths around of 20 until $30 \mathrm{~m}$.

\begin{tabular}{ccccccccc} 
& REF-A & REF-B & FER-A & FER-B & ULM-A & ULM-B & BTP-A & BTP-B \\
cop + e-cop $\left(\mathrm{Mg} \mathrm{g}^{-1}\right)$ & 0.06 & $<D L$ & 0.17 & 0.09 & 0.06 & 0.12 & 0.12 & 0.14 \\
Total LABs $\left(\mathrm{ng} \mathrm{g}^{-1}\right)$ & $<\mathrm{DL}$ & $<\mathrm{DL}$ & 42.5 & 46.5 & $<\mathrm{DL}$ & $<\mathrm{DL}$ & $<\mathrm{DL}$ \\
\hline
\end{tabular}

$<\mathrm{DL}$ : below detection limit ( $0.01 \mu \mathrm{g} \mathrm{g}^{-1}$ to fecal sterols and $1.0 \mathrm{ng} \mathrm{g}^{-1}$ to LABs). 


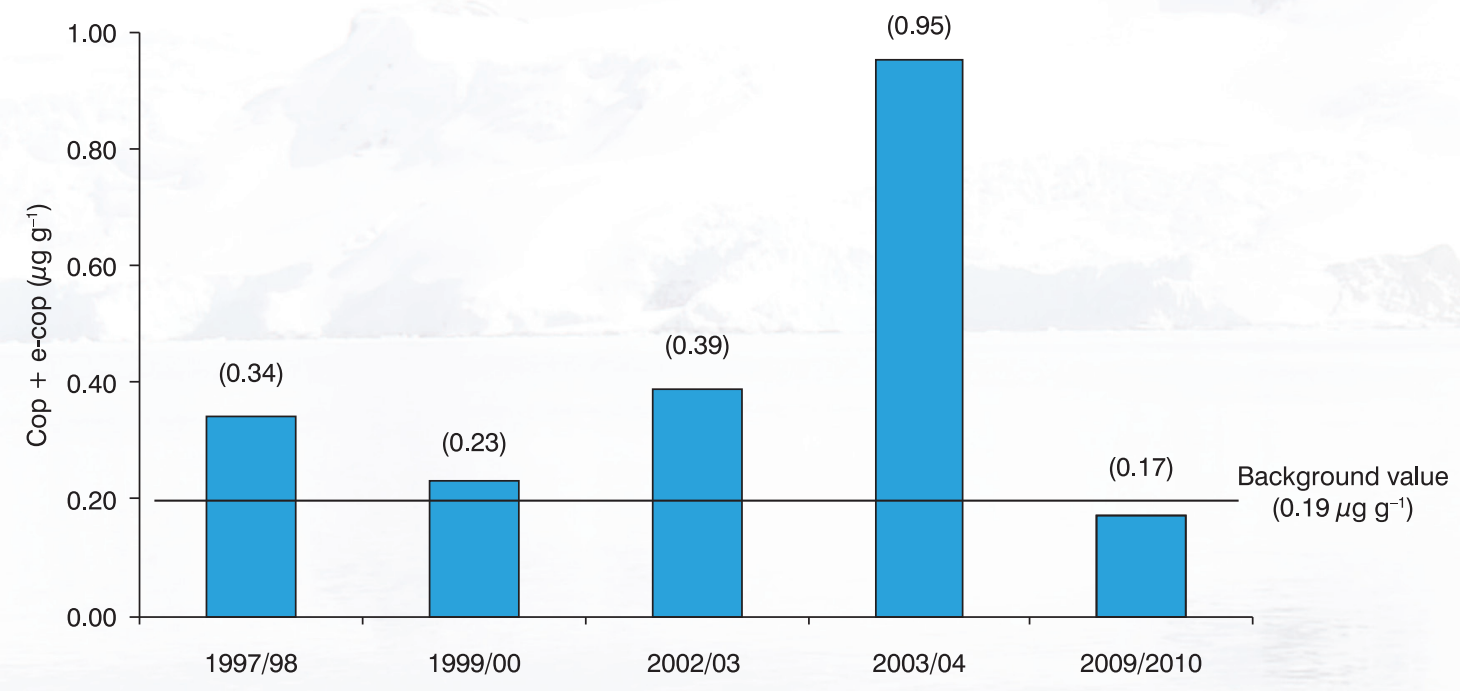

Figure 2. Fecal sterols in marine sediments in the vicinity of the EACF (10-20 m depth) in the austral summer from 1997/98 to 2009/10. The line at $0.19 \mu \mathrm{g}$ suggests the background value for Martel Inlet.

concentrations of fecal sterols in sediments near the Ferraz outfall (10-20 $\mathrm{m}$ depth) were plotted together, as shown in Figure 2 .

The sewage contribution gradually increases until 2003/04 as a result of the human population doubling at Ferraz Station over time. However, after this period, the concentrations declined as result of some adaptation to the sewage outfall used to discharge the treated waste water. The sewage contribution to Admiralty Bay is still under control because of local hydrodynamic conditions, especially due to tidal effects, which have favored the dispersion of the sewage effluent in the shallow coastal zone at Martel Inlet and the levels found in this study are lower than suggested by Gonzalez-Oreja \& Saiz-Salinas (1998) as indicator of sewage contamination $\left(>0.50 \mu \mathrm{g} \mathrm{g}^{-1}\right)$. The maximum concentration to fecal sterols $\left(0.17 \mu \mathrm{g} \mathrm{g}^{-1}\right)$ is close to the value previously calculated as background level to Martel Inlet (0.19) what confirms the statement above.

Total LABs were found only at sites close to Ferraz Station (FER-A and FER-B) and it was around 42.5 and $46.5 \mathrm{ng} \mathrm{g}^{-1}$. Further, total LABs found at sites in the current study, in general, are very low compared to levels at Davis Station (510 $\mathrm{ng} \mathrm{g}^{-1}$ ) (Green \& Nichols, 1995). However, the levels are similar or slightly higher compared to a previous studies released at Admiralty Bay (12 $\mathrm{ng} \mathrm{g}^{-1}$ - Martins et al., 2002; 35 ng.g ${ }^{-1}-$ Montone et al., 2010).
In general, higher concentrations of LABs with 11 up to 13 carbon atoms were observed, being coincident with the main mixture of Cm-LABs $(m=10-14)$ used in Brazil, with the percentage of each isomer group as follows: $5-16 \%$ ( $\mathrm{C}_{10}$-LABs), 28-45\% ( $\mathrm{C}_{11}$-LABs), 25-30\% ( $\mathrm{C}_{12}$-LABs), 10 $30 \%\left(\mathrm{C}_{13}\right.$-LABs $)$ and $<1.0\left(\mathrm{C}_{14}\right.$-LABs $)$.

The values of the I/E ratio in FER-A and FER-B varied from 0.52 to $0.59\left(\mathrm{C}_{11}-\mathrm{LABs}\right), 0.81$ to $0.89\left(\mathrm{C}_{12}\right.$-LABs $)$ and 0.70 to $0.75\left(\mathrm{C}_{13}\right.$-LABs). The low $\mathrm{I} / \mathrm{E}$ ratio is probably a result of wastewater discharge with primary treatment and reduced aerobic degradation.

\section{Conclusions}

The concentrations of the sewage organic markers were relatively low or undetectable away from the vicinity of Ferraz Station, considered the main source of sewage input to Admiralty Bay, while high concentration of fecal sterols and LABs occurred close to sewage outfall from Ferraz Station. However, the concentrations of these markers were lower than previous studies developed in Admiralty Bay and other regions of Antarctica.

Despite of low concentrations of sewage organic markers, monitoring programs are required to determine continuing trends and prevent the increase of anthropogenic impacts. 


\section{Acknowledgements}

C.C. Martins, S.N. Aguiar and L. M. M. Ceschim thank those responsible for the PQ-2 Grant (CNPq 307110/2008-7), the scholarship (PIBIC/CNPq) and for DTI-3 scholarship (CNPq 382434/2009-9), respectively. This work integrates the National Institute of Science and Technology Antarctic Environmental Research (INCTAPA) that receives scientific and financial support from the National Council for Research and Development $(\mathrm{CNPq}$ process: $\mathrm{n}^{\circ}$ 574018/2008-5) and Carlos Chagas Research Support Foundation of the State of Rio de Janeiro (FAPERJ $n^{\circ}$ E-16/170.023/2008). The authors also acknowledge the support of the Brazilian Ministries of Science, Technology and Innovation (MCTI), of Environment (MMA) and InterMinistry Commission for Sea Resources (CIRM). The data set of this work were also published in Marine Pollution Bulletin v.64 (2012), p.2867-2870.

\section{References}

Gonzalez-Oreja, J.A. \& Saiz-Salinas, J.I. (1998). Short-term spatio-temporal changes in urban pollution by means of faecal sterols analysis. Marine Pollution Bulletin, 36: 868-75.

Green, G. \& Nichols, P.D. (1995). Hydrocarbons and sterols in marine sediments and soils at Davis Station, Antarctica: a survey for human-derived contaminants. Antarctic Science ,7: 137-44.

Gröndahl, F.; Sidenmark, J. \& Thomsen, A. (2008). Survey of waste water disposal practices at Antarctic research stations. Polar Research, 28: 298-306.

Hughes, K.A. \& Thompson, A. (2004). Distribution of sewage pollution around a maritime Antarctic research station indicated by faecal coliforms, Clostridium perfringens and faecal sterol markers. Environmental Pollution, 127: 315-21.

Kawakami, S.K. \& Montone, R.C. (2002). An efficient ethanol-based analytical protocol to quality fecal steroids in marine sediments. Journal of Brazilian Chemical Society, 13: 226-32.

Martins, C.C.; Bícego, M.C. Mahiques, M.M. Figueira, R.C.L. Tessler, M.G. \& Montone, R.C. (2010). Depositional history of sedimentary linear alkylbenzenes (LABs) in a large South American industrial coastal area (Santos Estuary, Southeastern Brazil). Environmental Pollution, 158: 3355-64.

Martins, C.C.; Montone, R.C. Gamba, R.C. \& Pellizari, V.H. (2005). Sterols and fecal indicator microorganisms in sediments from Admiralty Bay, Antarctica. Brazilian Journal of Oceanography, 53: 1-12.

Martins, C.C.; Venkatesan, M.I. \& Montone, R.C. (2002). Sterols and linear alkylbenzenes in marine sediments from Admiralty Bay, King George Island, South Shetland Islands. Antarctic Science, 14: 244-52.

Martins, C.C.; Aguiar, S.N. Bícego, M.C. \& Montone, R.C. (2012). Sewage organic markers in surface sediments around the Brazilian Antarctic station: Results from the 2009/10 austral summer and historical tendencies. Marine Pollution Bulletin, 64: 2867-70.

Montone, R.C.; Martins, C.C.; Bícego, M.C.; Taniguchi, S.; Silva, D.A.M.; Campos, L.S. \& Weber, R.R. (2010). Distribution of sewage input in marine sediments around a maritime Antarctic research station indicated by molecular geochemical indicators. Science of the Total Environment, 408: 4665-71.

Santos, I.R.; Fávaro, D.I.T.; Schaefer, C.E.G.R. \& Silva-Filho, E.V. (2007). Sediment geochemistry in coastal maritime Antarctica (Admiralty Bay, King George Island): Evidence from rare earths and other elements. Marine Chemistry, 107: 464-74.

United Nations Environment Programme - UNEP. (1992). Determinations of petroleum hydrocarbons in sediments. Reference methods for marine pollution studies.

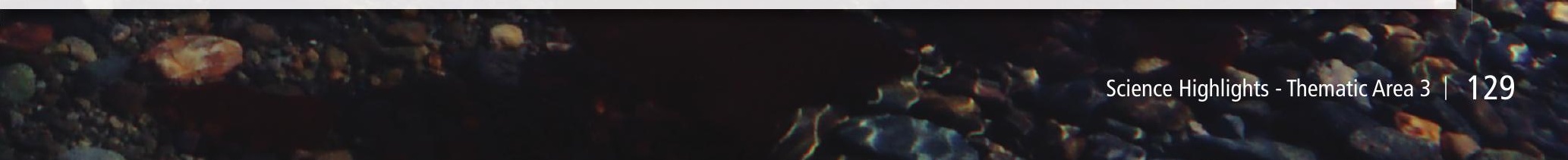

